\title{
Determination of Flavonoids and Resveratrol in Wine by Turbulent-Flow Chromatography-LC-MS
}

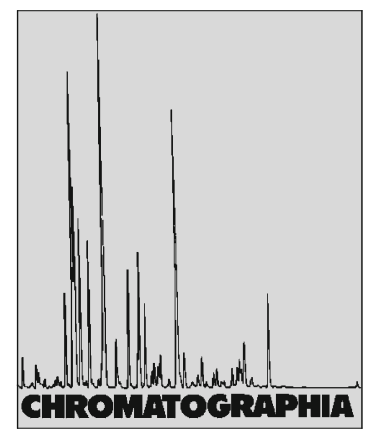

2009, 69, S167-S173

\author{
Michele Antoniuk Presta ${ }^{1,2}$, Ben Bruyneel' ${ }^{1}$, Renato Zanella ${ }^{2}$, Jeroen Kool ${ }^{1}$, Johannes G. Krabbe ${ }^{1}$, \\ Henk Lingeman ${ }^{1, \bowtie}$ \\ ${ }^{1}$ Faculty of Sciences, BioMolecular Analysis Section, VU University Amsterdam, De Boelelaan 1083, Amsterdam 1081 HV, The Netherlands; \\ E-Mail: h.lingeman@few.vu.nl \\ 2 Chemistry Department, Federal University of Santa Maria, 97105-900 Santa Maria, RS, Brazil
}

\begin{abstract}
Turbulent-flow chromatography (TFC) on-line coupled to liquid chromatography mass spectrometry (LC-MS) is used to determine flavonoids and resveratrol in different types of wines. A fully automated system was developed in which $10 \mathrm{~mL}$ of sample (diluted wine) was passed over a TFC column, after which the retained analytes were separated by reversedphase LC and detected by negative ion mode atmospheric-pressure chemical ionization (APCI) MS. The method proved to be fast, non-laborious, robust and sensitive. The feasibility of the method was tested on several red, white and rose wines. Quantitation of resveratrol was possible using the standard addition procedure. Red wine showed the highest amount of resveratrol $\left(4 \mathrm{mg} \mathrm{L}^{-1}\right)$, while rose and white wine contained concentrations which were about ten fold lower.
\end{abstract}

\section{Keywords}

Column liquid chromatography mass spectrometry

Turbulent-flow chromatography

Flavonoids

Resveratrol in wine

\section{Introduction}

Flavonoids are a group of structurally related metabolites originating from

Separation Analysis Applied to Pharmaceutical Sciences in Brazil. plants and as a result these compounds can be present in food and beverages [1]. These solutes possess a variety of biochemical properties ranging from antioxidant [2] to anti-carcinogenic [3] activity. In addition they are used against coronary diseases [4] and they possess antimicrobial properties.

Resveratrol (3,4',5-trihydroxystilbene) is an interesting compound found in peanuts, berries, grapes and wine. This natural phytoalexin is expressed in plants in response to fungal infections and stress factors such as nutrient deprivation $[5,6]$. Recent studies have shown that it has anti-carcinogenic [7, 8] and anti-angiogenic [9] properties. Moreover, resveratrol has been shown to bind to the $\alpha$ and $\beta$ estrogen receptors indicating a potential effect on cellular metabolism [10]. Finally, resveratrol has also been shown to extend the lifespan of yeast cells [11].

This selection already demonstrates the importance of resveratrol and flavonoids as well as the importance of having methods available to analyze these types of samples.

Due to processing of the plants to produce food and beverages the flavonoids and their favorable properties might be affected and lost, resulting in a lower abundance in the processed food products [12]. Moreover, some flavonoids originally present in low concentrations in plants could be undetectable with conventional analytical methods, although they might have significant 
biochemical properties. Next to the low abundance of the analytes, food products contain other constituents such as sugars, proteins and pigments which are present in significantly higher concentrations and can interfere with the analysis. This explains why sample clean-up and sample pre-concentration is necessary. Depending on the matrix and the interfering compounds different types of sample treatment such as solid-phase extraction (SPE) [13, 14], liquid-liquid extraction (LLE) [15] and solid-phase micro-extraction (SPME) can be used. In general these sample treatment steps are performed off-line with the result that they are laborious, and time consuming. After sample pretreatment the pretreated sample is introduced into the analytical system which can be either gas chromatography (GC) [16], capillary electrophoresis (CE) [17] or, normally, liquid chromatography (LC) [18]. Detection is performed by UV absorbance, mass spectrometry (MS) or nuclear-magnetic resonance (NMR) [13].

An interesting approach in sample clean-up and concentration is the use of turbulent-flow chromatography (TFC), which is especially suitable for samples containing low-molecular weight analytes and low- and high-molecular weight interferences. The phenomenon responsible for the improved clean-up efficiency at the onset of turbulence is an increase of the mass transfer rate through the formation of "eddies" (swirling of a fluid when it flows over an obstacle) in the mobile phase [19]. In TFC these "eddies" improve mass transfer resulting in the rapid removal of macromolecules based on size-exclusion mechanisms while small molecules are retained in the hydrophobic pores of the particles [20].

In the present study the use of TFC as a simple and automated sample cleanup and sample concentration step is demonstrated. The clean-up unit is coupled on-line with the LC-MS separation unit for an efficient detection and identification of the various flavonoids. The method was tested by analyzing flavonoids and resveratrol in wine. A relatively large volume of wine was introduced at a high flow rate onto the TFC-column, followed by a washing step to remove interfering compounds.
After the sample treatment the TFC column was switched on-line with the LC-column after which a gradient was started, extracting the retained compounds from the TFC-column towards the LC-MS.

The main advantage of the proposed method for the determination of flavonoids in liquid samples is that laborious and time-consuming extraction and preconcentration procedures can be avoided [21], because the samples (after dilution/ filtration) are directly subjected to the online sample treatment and analysis system.

\section{Experimental}

\section{Wine}

All studied white, red and rose wine samples were purchased at local supermarkets in Amsterdam (the Netherlands).

\section{Chemicals and Reagents}

Flavonoid standards of biochanin A, daidzein, genistein, hesperetin, resveratrol were purchased from Sigma-Aldrich (Zwijndrecht, Netherlands), naringenin was obtained from Carl Roth $\mathrm{GmbH}$ (Karlsruhe, Germany) and ethynylestradiol came from Sigma-Aldrich (Zwijndrecht, Netherlands). Methanol and ethanol LC grade were purchased from Biosolv BV (Valkenswaard, Netherlands), while helium (99.999\%) and nitrogen $(99.999 \%)$, used for LC-MS analysis, came from Praxair (Vlaardingen, Netherlands). Water was produced by a Milli-Q System Academic Gradient A10, equipped with a Quantum Ultrapure cartridge and millipak 40, $0.22 \mu \mathrm{m}$ filter (Millipore, Amsterdam, Netherlands). Filtration was performed by using disposable Whatman FP 30/0.2 CA-S cellulose acetate filters (Whatman, Kent, UK).

\section{Preparation of Standard and Sample Solutions}

Stock (standard) solutions of the different standards were prepared in methanol in a concentration of $1,000 \mathrm{mg} \mathrm{L}^{-1}$. These stock solutions were shielded from light by aluminium foil and stored at $-20{ }^{\circ} \mathrm{C}$. They were further diluted in methanol-water mixtures immediately before the actual analysis. Wine samples were first diluted ten times with water and subsequently filtered over a $0.2 \mu \mathrm{m}$ filter to remove any solids that may clog the analytical system.

\section{Instrumentation}

The TFC-LC-MS (Fig. 1) analysis was performed using: Shimadzu (Columbia, USA) LC system, consisting of two LC10A LC pumps and a DGU-14A degasser (used to generate a flow rate of $4 \mathrm{~mL} \min ^{-1}$ through the TFC column), Shimadzu (Columbia, USA) LC pump LC-2010A HT (to perform the gradient), Thermo Fisher scientific (Waltham, USA) LCQ deca ion-trap mass spectrometer with APCI and ESI interfaces, Gilson (Middleton, USA) ASPEC system with 401 syringe pump. The TFC column was a Thermo scientific TurboFlow (Waltham, USA) C18, cartridge $(50 \times 1.0 \mathrm{~mm}$ i.d., $50 \mu \mathrm{m} / 60 \AA$ particles), and the analytical column was a Waters Symmetry (USA) C18 column $(100 \times 2.1 \mathrm{~mm}$ i.d., $3.5 \mu \mathrm{m}$ particles $)$.

Each analysis started (Fig. 1a) with the aspiration of sample by the ASPEC system, which was then used to fill the sample loop $(10 \mathrm{~mL})$. Meanwhile, the TFC cartridge was conditioned with $100 \%(v / v)$ of water. The analytical column was equilibrated at the same time. The six-port valve on the left was subsequently switched and the content of the sample loop was transferred to the TFC cartridge at a flow rate of $4 \mathrm{~mL} \min ^{-1}$ (Fig. 1b). At this point the analytes were trapped on the TFC cartridge. In order to remove small hydrophilic/hydrophobic interferences as well as macromolecular constituents, a wash step with $100 \%(v / v)$ water was applied during $6 \mathrm{~min}$ at the same flow rate. After the washing step, the six-port valve on the right was switched and the TFC cartridge was placed on-line with the LC-MS system (Fig. 1c). The gradient program (flow rate of $0.2 \mathrm{~mL} \mathrm{~min}^{-1}$ ) started with $5 \%(v / v)$ of methanol (in 
water) increasing to $45 \%(v / v)$ of methanol in $1 \mathrm{~min}$, followed by a isocratic period of $5 \mathrm{~min}$ at $45 \%(v / v)$ of methanol. Thereafter, the methanol concentration was increased to $100 \%(v / v)$ in $15 \mathrm{~min}$. After $5 \mathrm{~min}$ at $100 \%(v / v)$, the concentration of methanol was reduced in $1 \mathrm{~min}$ to the initial conditions of $5 \%$ $(v / v)$ methanol to re-equilibrate the column. During these steps, the compounds trapped on the TFC cartridge were eluted to the analytical column, separated and finally detected by MS. After the analysis the valves were switched back to their original position (Fig. 1a) and the system was ready to start the next analysis. It is important to note that during sample aspiration (first step) both the TFC cartridge and the analytical column were further equilibrated with the starting conditions $(100 \% v / v$ water or $5 \%(v / v)$ methanol in water, respectively).

Determination of the breakthrough volume of the TFC cartridge was done by using one of the LC-10A HPLC units to pump ( $1 \mathrm{~mL} \mathrm{~min}^{-1}$ ) an aqueous solution spiked with the analyte $\left(2.5 \mathrm{mg} \mathrm{mL}^{-1}\right)$ over the TFC cartridge and by monitoring the effluent by the mass spectrometer equipped with the APCI-probe.

Optimization of the APCI conditions was performed by means of flow injection of the standards using the autosampler and pumps of the LC-1010A HT system. Standard solutions (50\% $(v / v)$ of methanol) were injected into a flow rate of $0.2 \mathrm{~mL} \mathrm{~min}{ }^{-1}$ which was directed into the APCI probe of the mass spectrometer without any separation. Optimization of the ESI parameters was done by direct infusion with the syringe pump on the LCQ Deca mass spectrometer.

\section{Results and Discussion}

\section{Optimization of the Mass Spectrometric Detection}

In order to optimize the mass spectrometric detection, APCI and ESI spectra were acquired both in the positive ion (PI) and negative ion (NI) mode in the range of $m / z \quad 50-600$. ESI tests were performed by direct infusion of a
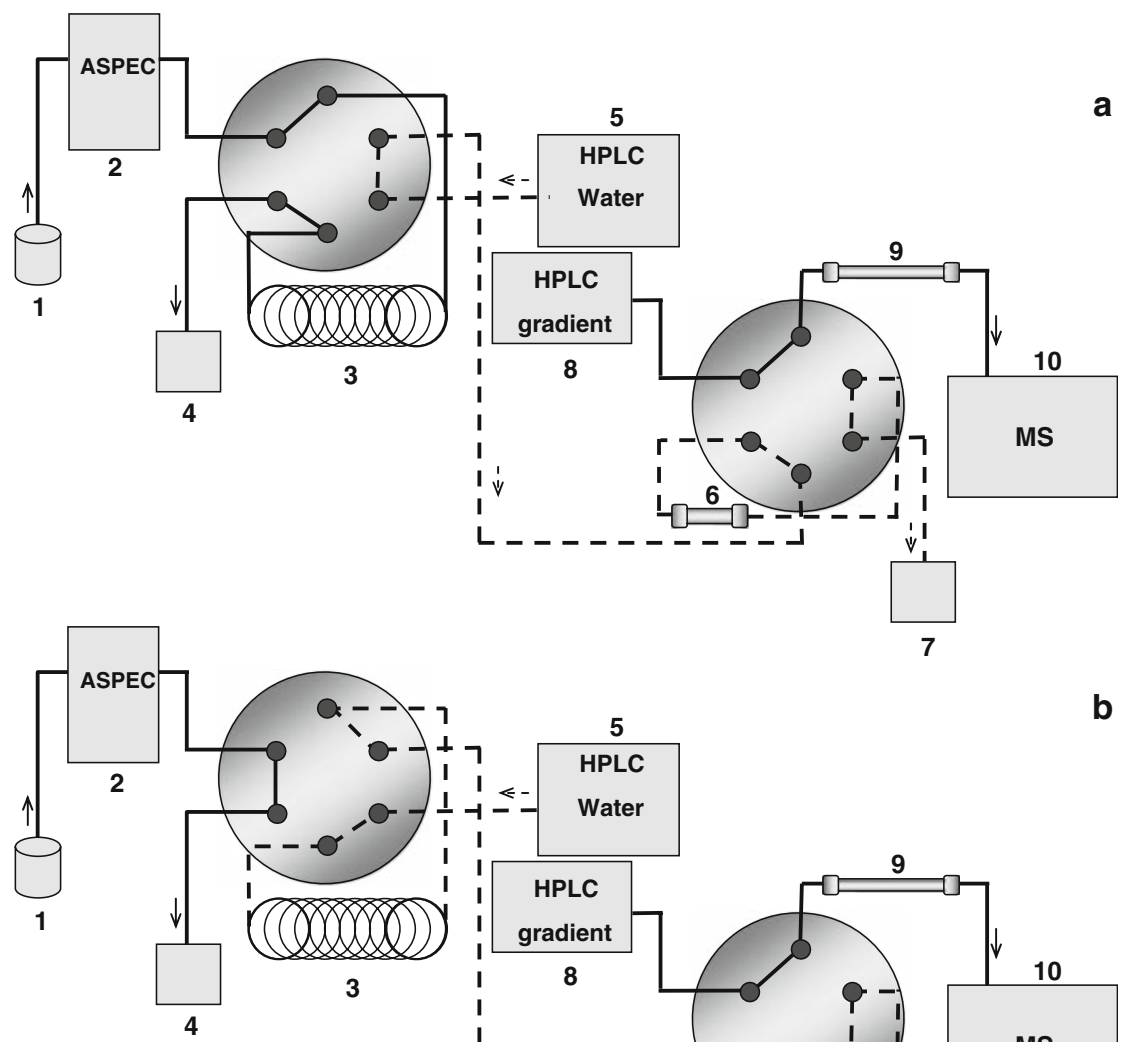

b
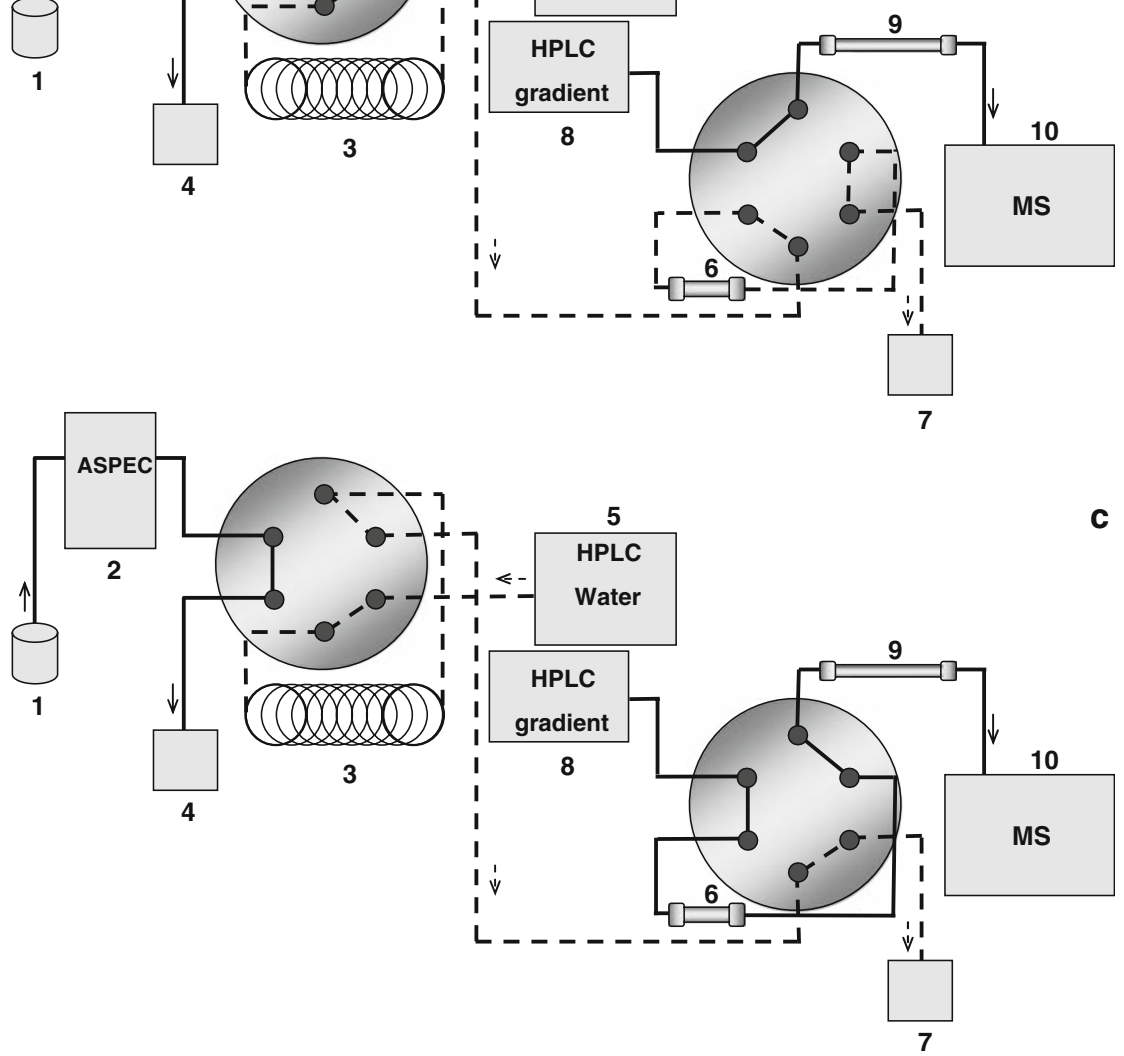

Fig. 1. On-line set-up of the TFC-LC-MS system. The position of the various valves to perform the sample clean-up and subsequent analysis of the samples is shown. a Filling the sample loop; b transfer from the sample loop to the TFC column followed by washing; c elution from the TFC cartridge to the $\mathrm{C} 18$ column using the gradient. 1. Sample; 2 . ASPEC system with syringe pump; 3. Sample loop (10 mL); 4. Waste; 5. HPLC Pump (4 mL min $\left.{ }^{-1}\right)$; 6. TFC Column; 7. Waste; 8. HPLC Pump (gradient); 9. HPLC Column (C18); 10. LCQ Deca Mass Spectrometer

$13.5 \mathrm{mg} \mathrm{L}^{-1}$ solution of daidzein and genistein. In the positive ion mode there was adduct formation for both com- pounds, while the negative ion mode gave low signal for both compounds and adduct formation for genistein was 
Table 1. Breakthrough volumes of the TFC column for different compounds using different concentrations of ethanol $(>50=$ more than $50 \mathrm{~mL})$

\begin{tabular}{|c|c|c|c|c|c|c|c|c|}
\hline \multirow{3}{*}{$\begin{array}{l}\text { Concentration } \\
\text { Ethanol (\%) } \\
\text { Compounds }\end{array}$} & \multicolumn{4}{|c|}{$2.5 \mathrm{mg} \mathrm{L}^{-1}$} & \multicolumn{4}{|c|}{$0.25 \mathrm{mg} \mathrm{L}^{-1}$} \\
\hline & 0 & 2.5 & 5 & 10 & 0 & 2.5 & 5 & 10 \\
\hline & \multicolumn{4}{|c|}{ Volume (mL) } & \multicolumn{4}{|c|}{ Volume (mL) } \\
\hline Resveratrol & 32 & 32 & 30 & 1 & 32 & 32 & 30 & 7 \\
\hline Daidzein & $>50$ & $>50$ & 32 & 1 & $>50$ & $>50$ & 32 & 11 \\
\hline Genistein & $>50$ & $>50$ & 32 & 1 & $>50$ & $>50$ & 32 & 11 \\
\hline Ethynylestradiol & $>50$ & $>50$ & 32 & 1 & nd & nd & nd & nd \\
\hline
\end{tabular}

nd not determined

observed. Flow-injection tests $(10 \mu \mathrm{L})$ for APCI of the same solutions of daidzein and genistein showed a good signal for both compounds without adduct formation. As a result all further investigations were performed in the APCI mode. In order to find the best settings the capillary temperature was optimized by varying the temperature from 165 to $325^{\circ} \mathrm{C}$, the optimum temperature was found to be $225^{\circ} \mathrm{C}$. The vaporizer temperature was optimized by varying the temperature from 300 to $450{ }^{\circ} \mathrm{C}$ (optimum $450{ }^{\circ} \mathrm{C}$ ). The tests were initially performed both in the PI and NI mode, which showed that NI provided better signals. Therefore, all further optimizations were done for this mode only. The optimized conditions obtained for NI-APCI were: a capillary voltage of $-35 \mathrm{~V}$, a tube lens of $20 \mathrm{~V}$ and a corona discharge current of $10 \mu \mathrm{A}$. The sheath gas (nitrogen) flow rate for APCI was $80 \mathrm{AU}$ and the auxiliary gas (nitrogen) flow rate was 20 AU. Studies by other researchers comparing ESI and APCI, both in PI and NI mode concluded, that NI APCI is excellent for flavonoid analysis agreeing with our finding [21-23].

\section{Optimization of Chromatographic Conditions}

The conditions to use the TFC cartridge under optimum conditions were studied by measuring the breakthrough volumes of resveratrol, daidzein, genistein and the internal standard (ethynylestradiol). A large volume of a standard solution $(0$, $2.5,5$ or $10 \%(v / v)$ ethanol in Milli-Q water), spiked with $2.5 \mathrm{mg} \mathrm{L}^{-1}$ of analyte, was applied to the TFC-column at a flow rate of $1 \mathrm{~mL} \mathrm{~min}{ }^{-1}$, while the intensity of the $m / z$ of the compound was monitored by means of MS. The time after which the compound signal started to increase was used to calculate the breakthrough volume. The results are summarized in Table 1. Since wine contains about $13 \%(v / v)$ of ethanol, a concentration of $2.5,5$ and $10 \%(v / v)$ of ethanol was chosen as organic modifier tions were chosen to mimic the real-life conditions for the flavonoids to be trapped on the TFC-column. When $10 \%$ $(v / v)$ of ethanol was used as the sample matrix, the compounds were eluted in less than $1 \mathrm{~mL}$. For the $5 \%(v / v)$ ethanol containing sample, the breakthrough volumes were in the order of $30 \mathrm{~mL}$, and for the 2.5 and $0 \%(v / v)$ ethanol samples the breakthrough volumes were in all cases higher than $50 \mathrm{~mL}$. Since these breakthroughs might be caused also by mass overloading of the TFC column, a $25 \mu \mathrm{g} \mathrm{L}^{-1}$ genistein solution was investigated with the same concentrations of organic modifier as described above. These experiments showed similar breakthrough volumes proving that the results were not caused by mass overloading of the column.

From these experiments it was concluded that the wine samples must be diluted before the analysis. Wine contains about $13 \%(v / v)$ of ethanol, which means that it must be diluted at least three times to avoid breakthrough of the analytes on the TFC cartridge. Furthermore, the total volume used for sampling and washing of the TFC cartridge must in the standard solution. These condi- not exceed $30 \mathrm{~mL}$, otherwise the recovery of moderately polar compounds such as resveratrol will significantly decrease. As a result $10 \mathrm{~mL}$ of sample was transferred from the sample loop onto the cartridge during $2.5 \mathrm{~min}\left(4 \mathrm{~mL} \mathrm{~min}{ }^{-1}\right)$,

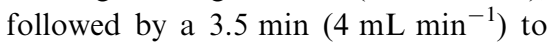
wash the TFC cartridge (Fig. 1b). In this case the total volume used was $24 \mathrm{~mL}$.

\section{Optimization Overall TFC-LC-MS System}

First of all the different standards were tested separately to study their behavior in the on-line system (data not shown). All of the tested solutes provided a high signal in the mass spectrometer, indicating that the on-line system was sufficiently retaining the compounds of interest. Thereafter, samples of red, white and rose wine were studied. In this case the sensitivity was a problem because of matrix interferences. The problem was solved by diluting the wine sample ten times instead of three times.

Resveratrol ( $m / z$ 227.2) was detected, but two peaks were observed in the chromatograms. To confirm that both peaks were originating from resveratrol $\mathrm{MS}^{2}$ experiments were performed. The $\mathrm{MS}^{2}$ data of both peaks, both in the standard and in the wine samples, were identical and showed the same fragmentation pattern. This is in agreement with the literature which shows that two isomers of resveratrol, trans- and cisresveratrol, can be present in wine [24, 25]. It also has been shown that transresveratrol can be converted to cis-resveratrol under the influence of UV light [25]. Since wine samples are normally stored in the presence of light, both isomers can be present. Based on the structures of the isomers and their retention factors, it is expected that the MS response will be about the same. As result, quantitation was performed by combining the areas of both isomers.

In red wine a peak with $m / z$ of 301.1 could be found. This peak indicated the presence of hesperetin. However, MS $^{2}$ spectra showed that this peak did not belong to one of the studied flavonoids. 


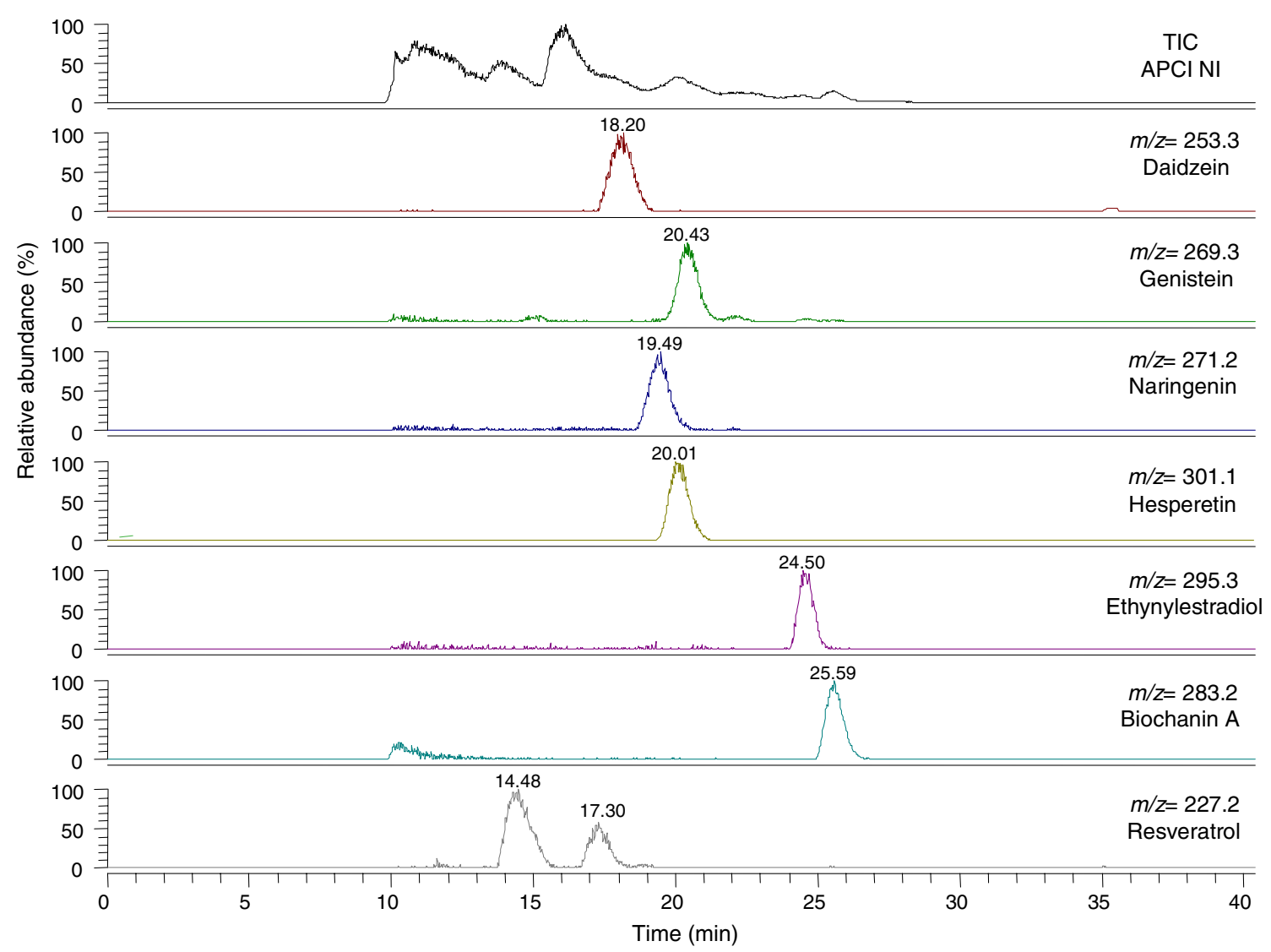

Fig. 2. Chromatogram of a red wine sample (diluted 10 times), spiked with $100 \mu \mathrm{g} \mathrm{L}^{-1}$ daidzein, genistein, naringenin, hesperetin, ethynylestradiol (internal standard; $50 \mu \mathrm{g} \mathrm{L}^{-1}$ ), biochanin A and resveratrol

\section{Method Validation}

In order to study the applicability of the on-line system to determine flavonoids in wine, the system was validated by determining the LOD and LOQ values. In Fig. 2 an example of an extracted-ion chromatogram of a spiked red wine sample is shown. Full scan MS is used for the analysis and extracted-ion chromatograms to calculate the peak areas of the test compounds, with the exception of hesperetin because of the presence of an interfering compound. $\mathrm{MS}^{2}$ of hesperetin and the interfering compound showed that most of the fragment ions of hesperetin $(m / z 242)$ were not present in the $\mathrm{MS}^{2}$ spectra of the interfering compound. Therefore, for the quantitation of hesperetin single reaction monitoring (SRM, parent $\mathrm{m} / \mathrm{z} 301.1$, detected $\mathrm{m} / \mathrm{z}$ 242) was applied.

The relatively high and varying background in the chromatograms made it necessary to use the standard-addition approach in order to accurately determine the detection limits. Resveratrol, for example, is always present in wine samples. The linear dynamic range was determined by spiking wine samples with increasing concentrations of the analytes. Good linearities were obtained with $r^{2}$ values of at least 0.99 , which is satisfactory for this type of measurements (Table 2) [26, 27].

The same data set was used to determine the LOD and LOQ values. The LOD was taken as three times the $\mathrm{S} / \mathrm{N}$ ratio and the LOQ being ten times the $\mathrm{S} / \mathrm{N}$ ratio. The results are presented in Table 3. All of the compounds showed detection limits at the ppb level, while the quantitation levels were in the sub-ppm range. Taken into account the relatively high background levels, this is more than satisfactory.

The method was further validated by testing the inter-day and intra-day repeatability. The intra-day repeatability was determined by injecting six times a sample with three different concentration levels. The inter-day repeatability was determined by injecting the same samples three times a day during three subsequent days. A 7-point calibration curve was constructed by injecting seven samples with increasing concentrations in the range of $0.05-2 \mathrm{mg} \mathrm{L}^{-1}$ for the flavonoids and for resveratrol in the range of $1-50 \mathrm{mg} \mathrm{L}^{-1}$. The intra-day precision varied from 0.3 to $11.4 \%$ for all wine (i.e., red, white, rose) samples, while the inter-day precision ranged from 2.4 to $17.8 \%$ for the same samples. These values are all within legal requirements which mention a precision of $\leq 20 \%$ [28].

\section{Application of the Method}

Three different white wines, one rose and four different red wines were selected to test the validated method for the presence of flavonoids and resveratrol. All 
Table 2. Linear ranges and regression coefficients for all compounds in the wines

\begin{tabular}{|c|c|c|c|c|c|c|}
\hline \multirow[t]{2}{*}{ Compound } & \multicolumn{2}{|l|}{ Red wine } & \multicolumn{2}{|l|}{ White wine } & \multicolumn{2}{|l|}{ Rose } \\
\hline & Linear $\left(\mathrm{mg} \mathrm{mL}^{-1}\right)$ & $R^{2}$ & Linear $\left(m g \mathrm{~mL}^{-1}\right)$ & $R^{2}$ & Linear $\left(\mathrm{mg} \mathrm{mL}^{-1}\right)$ & $R^{2}$ \\
\hline Biochanin A & $0.05-2$ & 0.9958 & $0.05-2$ & 0.9996 & $0.05-2$ & 0.9996 \\
\hline Daidzein & $0.05-2$ & 0.9826 & $0.05-1$ & 0.9992 & $0.05-2$ & 0.9984 \\
\hline Genistein & $0.05-2$ & 0.9920 & $0.05-1$ & 0.9987 & $0.05-2$ & 0.9967 \\
\hline Hesperetin & $0.05-2$ & 0.9886 & $0.05-1$ & 0.9953 & $0.05-1$ & 0.9969 \\
\hline Naringenin & $0.05-2$ & 0.9809 & $0.05-2$ & 0.9978 & $0.05-1$ & 0.9997 \\
\hline Resveratrol & $1-50$ & 0.9958 & $0.05-2$ & 0.9999 & $0.05-2$ & 0.9984 \\
\hline
\end{tabular}

Red wine $=$ Cabernet Sauvignon-Merlot, White wine $=$ Sauvignon Blanc, Rose $=$ Mooi Kaap

Table 3. Limits of quantification (LOD) \& limits of quantification (LOQ) in $\mu \mathrm{L}$ for all compounds in the wines. Red wine $=$ Cabernet Sauvignon Merlot, White wine $=$ Sauvignon Blanc Underraga, Rose $=$ Mooi Kaap

\begin{tabular}{|c|c|c|c|c|c|c|}
\hline \multirow[t]{2}{*}{ Compound } & \multicolumn{2}{|c|}{ Red wine } & \multicolumn{2}{|c|}{ White wine } & \multicolumn{2}{|l|}{ Rose } \\
\hline & LOD & LOQ & LOD & LOQ & LOD & LOQ \\
\hline Biochanin A & 11 & 36 & 5 & 18 & 6 & 21 \\
\hline Daidzein & 16 & 54 & 7 & 24 & 13 & 42 \\
\hline Genistein & 22 & 73 & 7 & 22 & 12 & 40 \\
\hline Hesperetin & 4 & 73 & 10 & 32 & 19 & 64 \\
\hline Naringenin & 11 & 15 & 2 & 6 & 3 & 9 \\
\hline Resveratrol & 18 & 60 & 21 & 70 & 34 & 113 \\
\hline
\end{tabular}

Table 4. Application of the method: determination of resveratrol in 8 different wines (red, rose and white)

\begin{tabular}{|lllr|}
\hline Wine & & & \multirow{2}{*}{ Resveratrol $\left(\mu \mathrm{g} \mathrm{L}^{-1}\right)$} \\
\hline Name & Type & Origin & \\
\hline Sauvignon Blanc & White & Chile & 210 \\
Lambrusco Blanc & White & Italy & 251 \\
Orvieto Blanc & White & Italy & 56 \\
Mooi Kaap & Rose & South Africa & 340 \\
La Tulipe Bordeaux & Red & France & 2,010 \\
Santa Julia Bonarda & Red & Argentina & 2,910 \\
Cabernet Sauvignon Merlot & Red & Chile & 4,310 \\
Doornbosch Rood & Red & South Africa & 2,120 \\
\hline
\end{tabular}

samples were diluted ten times to obtain a final ethanol concentration of ca. $1 \%$ $(v / v)$. The samples were first filtered and spiked with the internal standard (50 $\mathrm{g} \mathrm{L} \mathrm{L}^{-1}$ of ethynylestradiol). As mentioned before none of the flavonoids, used as test compounds, were found. On the contrary, resveratrol was present in all tested samples. Using the standardaddition procedure the concentrations found varied widely (Table 4). Red wines contained about ten to twenty times more resveratrol than white wines, while the rose wine studied contained somewhat higher concentrations compared with the white wines.

\section{Conclusions}

The successful combination of turbulentflow chromatography and LC-MS was demonstrated for the determination of flavonoids and resveratrol in wine samples. The applicability of the method was tested on several red, white and rose wines. Intra-day and inter-day precision for all wines and concentrations were calculated to be $<12$ and $<18 \%$, respectively. The method proved to be linear for all studied compounds, while the LOD values were in the order $0.005-$ $0.025 \mathrm{mg} \mathrm{L}^{-1}$.

There still is a growing interest in resveratrol because of its favorable biochemical properties. Quantitation of resveratrol was performed using the standard-addition procedure. Red wine showed the highest concentration of resveratrol $\left(4 \mathrm{mg} \mathrm{L}^{-1}\right)$, compared to rose and white wine which was at least 10-fold lower. Moreover, the different 
red wines contained also different amounts of resveratrol.

The presented method might be useful to determine the up or down regulation of flavonoids in aqueous samples (e.g., wine), which can provide information on the pesticides applied as well as the types of grapes used to produce the wine.

\section{Acknowledgments}

The authors acknowledge VU-ACAS (The Netherlands) for financial and scientific support and CAPES (Brazil) for the fellowship to M.A. Presta.

\section{Open Access}

This article is distributed under the terms of the Creative Commons Attribution Noncommercial License which permits any noncommercial use, distribution, and reproduction in any medium, provided the original author(s) and source are credited.

\section{References}

1. Hertog MGL, Hollman PCH, Katan MB, Kromhout D (1993) Nutr Cancer 20:21-29

2. Shahidi F, Wanasundara PK (1992) Crit Rev Food Sci Nutr 32:67-103
3. Knekt P, Järvinen R, Seppänen R, Heliövaara M, Teppo M, Pukkala E (1997) Am J Epidemiol 146:223-230

4. Hertog MGL, Feskens EJM, Hollman PCH, Katan MB, Kromhout D (1993) Lancet 342:1007-1011. doi:10.1016/01406736(93)92876-U

5. Milner JA, McDonald SS, Anderson DE, Greenwald P (2001) Nutr Cancer 41:1-16. doi:10.1207/S15327914NC41-1\&2 1

6. Baur JA, Sinclair DA (2006) Nat Rev Drug Discov 5:493-506. doi:10.1038/ nrd2060

7. Stewart JR, Artime MC, O'Brian CA (2003) J Nutr 133:2440S-2443S

8. Levi F, Pasche C, Lucchini F, Ghidoni R, Ferraroni M, la Vecchia C (2005) Eur J Cancer Prev 14:139-142. doi:10.1097/ 00008469-200504000-00009

9. Garvin S, Öllinger K, Dabrosina C (2006) Cancer Lett 231:113-122. doi:10.1016/ j.canlet.2005.01.031

10. Bowers JL, Tyulmenkov VV, Jernigan SC, Klinge CM (2000) Endocrinology 141:3657-3667. doi:10.1210/en.141.10. 3657

11. Howitz KT, Bitterman KJ, Cohen HY, Lamming DW, Lavu S, Wood JG (2003) Nature 425:191-196. doi:10.1038/nature 01960

12. Fang F, Li J-M, Pan Q-H, Huang W-D (2007) Food Chem 101:428-433. doi: 10.1016/j.foodchem.2005.12.036

13. Svedström U, Vuorela H, Kostiainen R, Laakso I, Hiltunen R (2006) J Chromatogr A 1112:103-111. doi:10.1016/ j.chroma.2005.12.080

14. Vinha AF, Ferreres F, Silva BM, Valentão P, Gonçalves A, Pereira JA et al (2005) Food Chem 89:561-568. doi: 10.1016/j.foodchem.2004.03.012

15. Rodríguez-Delgado MA, Malovaná S, Pérez JP, Borges T, García Montelongo FJ (2001) J Chromatogr A 912:249-257. doi:10.1016/S0021-9673(01)00598-2
16. Fiamegos YC, Nanos CG, Vervoort J, Stalikas CD (2004) J Chromatogr A 1041:11-18. doi:10.1016/j.chroma.2004. 04.041

17. Kočevar N, Glavač I, Injac R, Kreft S (2008) J Pharm Biomed Anal 46:609-614. doi:10.1016/j.jpba.2007.11.016

18. Griffith AP, Collison MW (2001) J Chromatogr A 913:397-413. doi:10.1016/ S0021-9673(00)01077-3

19. Mullet WM (2007) J Biomed Biophys Methods 70:263-273

20. Du L, Musson DG, Wang AQ (2005) Rapid Commun Mass Spectrom 19:17791787. doi: $10.1002 / \mathrm{rcm} .1984$

21. Justesen U, Knuthsen P, Leth T (1998) J Chromatogr A 799:101-110. doi:10.1016 S0021-9673(97)01061-3

22. Justesen U (2000) J Chromatogr A 902:369-379. doi:10.1016/S0021-9673(00) 00861-X

23. de Rijke E, Zappey H, Ariese F, Gooijer C, Brinkman UAT (2003) J Chromatogr A 984:45-58. doi:10.1016/S0021-9673 (02)01868-X

24. Buiarelli $\mathrm{F}$, Coccioli $\mathrm{F}$, Jasionowska R, Merolle M, Terracciano A (2006) Chromatographia 64:475-481. doi:10.1365 s10337-006-0042-4

25. Montsko G, Nikfardjam MSP, Szabo Z, Boddi $\mathrm{K}$, Lorabd $\mathrm{T}$, Ohmacht $\mathrm{R}$ et al (2008) J Photochem Photobiol Chem 196:44-50.

doi: 10.1016/j.jphotochem.2007.11.011

26. Ribani M, Bottoli CBG, Collins $\mathrm{CH}$, Jardim ICSF, Melo LFC (2004) Quim Nova 27(5):771-780. doi:10.1590/S010040422004000500017

27. DOQ-CGCRE-08 Revisão 2 (2007) Instituto Nacional de Meterologia, Normalização e Qualidade Industrial

28. SANCO 2007/3131 3rd edition (2007) Commission of the European Communities 